\title{
Inhibition of Neuronal Nitric Oxide Synthase Increases Aggressive Behavior in Mice
}

Gregory E. Demas, ${ }^{1}$ Mikael J. L. Eliasson, ${ }^{2,3}$ Ted M. Dawson, ${ }^{2,6}$ Valina L. Dawson, ${ }^{2,5,6}$ Lance J. Kriegsfeld, ${ }^{1}$ Randy J. Nelson, ${ }^{1,2}$ and Solomon H. Snyder ${ }^{2,3,4}$

Johns Hopkins University, ${ }^{1}$ Department of Psychology, Behavioral Neuroendocrinology Group, Baltimore, Maryland, U.S.A. Johns Hopkins University, School of Medicine, Departments of ${ }^{2}$ Neuroscience, ${ }^{3}$ Pharmacology and Molecular Sciences, ${ }^{4}$ Psychiatry, ${ }^{5}$ Physiology, and ${ }^{6}$ Neurology, Baltimore, Maryland, U.S.A.

\begin{abstract}
Background: Mice with targeted disruption of the gene for the neuronal isoform of nitric oxide synthase (nNOS) display exaggerated aggression. Behavioral studies of mice with targeted gene deletions suffer from the criticism that the gene product is missing not only during the assessment period but also throughout development when critical processes, including activation of compensatory mechanisms, may be affected. To address this criticism, we have assessed aggressive behavior in mice treated with a specific pharmacological inhibitor of nNOS.

Materials and Methods: Aggressive behavior, as well as brain citrulline levels, were monitored in adult male mice after treatment with a specific nNOS inhibitor, 7nitroindazole (7-NI) $(50 \mathrm{mg} / \mathrm{kg}$ ip), which is known to reduce NOS activity in brain homogenates by $>90 \%$. As controls, animals were treated with a related indazole,
\end{abstract}

3-indazolinone (3-I) $(50 \mathrm{mg} / \mathrm{kg}$ ip) that does not affect nNOS, or with an oil vehicle.

Results: Mice treated with 7-NI displayed substantially increased aggression as compared with oil- or 3-I-injected animals when tested in two different models of aggression. Drug treatment did not affect nonspecific locomotor activities or body temperature. Immunohistochemical staining for citrulline in the brain revealed a dramatic reduction in 7-NI-treated animals.

Conclusions: 7-NI augmented aggression in WT mice to levels displayed by nNOS - mice, strongly implying that nNOS is a major mediator of aggression. NOS inhibitors may have therapeutic roles in inflammatory, cardiovascular, and neurologic diseases. The substantial aggressive behavior soon after administration of an nNOS inhibitor raises concerns about adverse behavioral sequelae of such pharmacological agents.

\section{INTRODUCTION}

Nitric oxide (NO) is formed by several subtypes of nitric oxide synthase (NOS) associated with the different functions of NO throughout the body. Blood pressure is regulated by endothelial NOS (eNOS), macrophage function is modulated by inducible NOS (iNOS), while the neurotrans-

Address correspondence and reprint requests to: Dr. Solomon H. Snyder, Johns Hopkins University School of Medicine, Depts. of Neuroscience, Pharmacology and Molecular Sciences, and Psychiatry, 725 North Wolfe Street, Baltimore, MD 21205, U.S.A. Phone: 410-955-3024; Fax: 410-955-3623; e-mail: sol_snyder@qmail.bs.jh.edu mitter pool of NO is synthesized primarily by neuronal NOS (nNOS), though central nervous system neurons also may possess eNOS (1). Efforts to understand the role of NO in brain function have been assisted by the availability of mice with targeted disruption of nNOS (nNOS-) (2). These mice resist brain damage following middle cerebral artery occlusion (3). nNOS- animals display distended stomachs with hypertrophied pyloric sphincters which is associated with disorders in gastrointestinal motility and reflects loss of nNOS in myenteric plexus neurons (2).

Much of the behavior of nNOS- animals 
appears grossly normal with no defects observed in locomotor activity, breeding $(4,5)$, long-term potentiation in the hippocampus (6), long-term depression in the cerebellum (7), and overall sensorimotor function (4). However, male nNOS - animals display dramatic increases in aggressive behavior and excessive inappropriate sexual behavior (4).

Like most other gene knockout mice, nNOS - animals were created utilizing stem cells from 129SvEv animals injected into C57BL/6J mice, thus the knockout animals are a hybrid of two strains. It has been suggested that this mixture of strains could contribute to nNOS- behavioral abnormalities (8). Also, because nNOSmice have lacked the gene from an early embryonic stage, subsequent physiological adaptations may have contributed to the behavioral abnormalities.

To overcome these difficulties, we have used a drug that specifically inhibits nNOS. Many studies of NO physiology have employed arginine-derived NOS inhibitors that inhibit all three forms of NOS. Inhibition of eNOS results in substantial increases in blood pressure that can alter cerebral perfusion with associated behavioral deficits. Recently, 7-nitroindazole (7-NI) has been reported to inhibit nNOS in intact animals with no blood pressure elevation (9). In the present study we report that 7-NI administration evokes a substantial increase in aggressive behavior of male mice, resembling effects observed in nNOS - animals.

\section{MATERIALS AND METHODS}

\section{Materials}

The citrulline antiserum has been previously described (10). A polyclonal antiserum to the C-terminal region of human nNOS (residues 1419-1433) was kindly provided by Jeffrey Spangenberg (IncStar, Stillwater, MN) and used at a 1:15,000 dilution. Glutaraldehyde was from EM Sciences (Ft. Washington, PA). The peroxidase Elite staining kit was from Vector Laboratories (Burlingame, CA). All other reagents were from Sigma (St. Louis, MO). 3-Indazolinone was from Aldrich (Milwaukee, WI) and 7-NI from Calbiochem (Cambridge, MA).

\section{Animals and Housing Conditions}

Twenty adult male house mice (Mus musculus) of the C57BL/6J strain were obtained from Jackson
Laboratories. All animals were 4-6 months of age (i.e., sexually mature) at the onset of behavioral testing. Mice were individually housed in polypropylene cages in a colony room with a 24-hr light-dark (LD) 16:8 light cycle (lights on at $0600 \mathrm{hr}$ Eastern Standard Time [EST]). Relative humidity was maintained at $50 \pm 5 \%$. Food (Agway Prolab 1000, Syracuse, NY) and tap water were provided ad libitum throughout the experiment.

\section{Drug Administration}

Animals were randomly divided into one of three groups. Experimental animals received 0.1 $\mathrm{ml}$ injections of either 7-NI or $3-\mathrm{I}(50 \mathrm{mg} / \mathrm{kg}$ dissolved in sesame oil) while control animals received $0.1 \mathrm{ml}$ of oil vehicle alone. 3-I, a compound that closely matches the indazole structure but does not inhibit nNOS in vitro (9) or in vivo (11), was used as a control for any nonspecific effects of drug treatment on behavior. All animals received three daily injections (at 0800, 1600 , and $2400 \mathrm{hr}$ EST) across 4 consecutive days. Behavioral testing began at $1630 \mathrm{hr}$ on the fourth day (i.e., $30 \mathrm{~min}$ after the last injection). This regimen has been shown to cause $>90 \%$ inhibition of nNOS activity in brain homogenates (12).

\section{Aggression Tests}

RESIDENT-INTRUDER AGGRESSION. Adult, male stimulus mice (i.e., intruders) were introduced into the home cage of either an experimental or control adult male mouse. Intruder mice were marked on the tail with an indelible marker for purposes of identification. The bedding in the home cages remained unchanged for 10 days prior to testing. The latency to first aggressive encounter, the duration of each aggressive encounter, and the total number of aggressive encounters initiated by the resident male were recorded. Aggression tests lasted $5 \mathrm{~min}$ and were conducted each day for 3 consecutive days between 1500 and $1700 \mathrm{hr}$. Aggressive behaviors scored included chasing, biting, and offensive attacks. A novel pairing of animals was made for each consecutive test and intruder males were not used more than once per day.

GROUPED AGGRESSION IN NEUTRAL ARENA. Four adult control or experimental mice were simultaneously introduced into a clear glass aquarium 
$(38.5 \times 26.5 \times 30.7 \mathrm{~cm})$. The floors of the aquaria were covered with $2-3 \mathrm{~cm}$ of fresh pine shavings. The latency to first aggressive encounter, the duration of each aggressive encounter, and the total number of aggressive encounters initiated by each male were recorded. Aggression tests lasted $15 \mathrm{~min}$ and were conducted between 1500 and $1700 \mathrm{hr}$.

\section{Immunocytochemistry for Citrulline and nNOS}

A random subset of two animals from each experimental condition were killed immediately after behavioral testing for immunohistochemical analysis. Anesthetized animals were perfused through the left ventricle for $30 \mathrm{sec}$ with $37^{\circ} \mathrm{C}$ oxygenated Krebs/Henseleit buffer and then at $15 \mathrm{ml} / \mathrm{min}$ with $250 \mathrm{ml}$ of $37^{\circ} \mathrm{C} 5 \%$ glutaraldehyde $/ 0.5 \%$ paraformaldehyde containing $0.2 \%$ $\mathrm{Na}_{2} \mathrm{~S}_{2} \mathrm{O}_{5}$ in $0.1 \mathrm{M}$ sodium phosphate ( $\mathrm{pH} 7.4$ ). Brains were postfixed in the same buffer for $2 \mathrm{hr}$ at room temperature. After cryoprotection for 2 days at $4^{\circ} \mathrm{C}$ in $50 \mathrm{mM}$ sodium phosphate, $\mathrm{pH}$ 7.4/0.1 M NaCl/20\% (vol/vol) glycerol, brain sections $(40 \mu \mathrm{m})$ were cut on a sliding microtome. Free-floating brain sections were reduced for 20 min with $0.5 \% \mathrm{NaBH}_{4}$ and $0.2 \%$ $\mathrm{Na}_{2} \mathrm{~S}_{2} \mathrm{O}_{5}$ in phosphate-buffered saline (PBS) (10 $\mathrm{mM}, \mathrm{pH} 7.4 / 0.19 \mathrm{M} \mathrm{NaCl}$ ), washed for $45 \mathrm{~min}$ at room temperature in PBS containing $0.2 \%$ $\mathrm{Na}_{2} \mathrm{~S}_{2} \mathrm{O}_{5}$, blocked with $4 \%$ normal goat serum for $1 \mathrm{hr}$ in the presence of $0.2 \%$ Triton $\mathrm{X}-100$, and incubated overnight at $4^{\circ} \mathrm{C}$ with the primary antiserum diluted in PBS containing $2 \%$ goat serum and $0.1 \%$ Triton $X-100$. The citrulline and nNOS antisera were used at 1:10,000 and $1: 15,000$ dilutions, respectively. Immunoreactivity was visualized with the Vectastain $\mathrm{ABC}$ Elite kit. Immunohistochemistry was routinely done in the presence of liquid-phase glutaraldehyde conjugates of L-arginine and L-glutamate to minimize any cross-reactivity to amino acids with similar structure to citrulline that occur in high concentrations in brain.

\section{RESULTS}

\section{7-Nitroindazole Increases Aggressive Behavior}

7-NI-treated animals displayed substantially greater aggression than littermates treated with vehicle control (Fig. 1). Compared to controls,
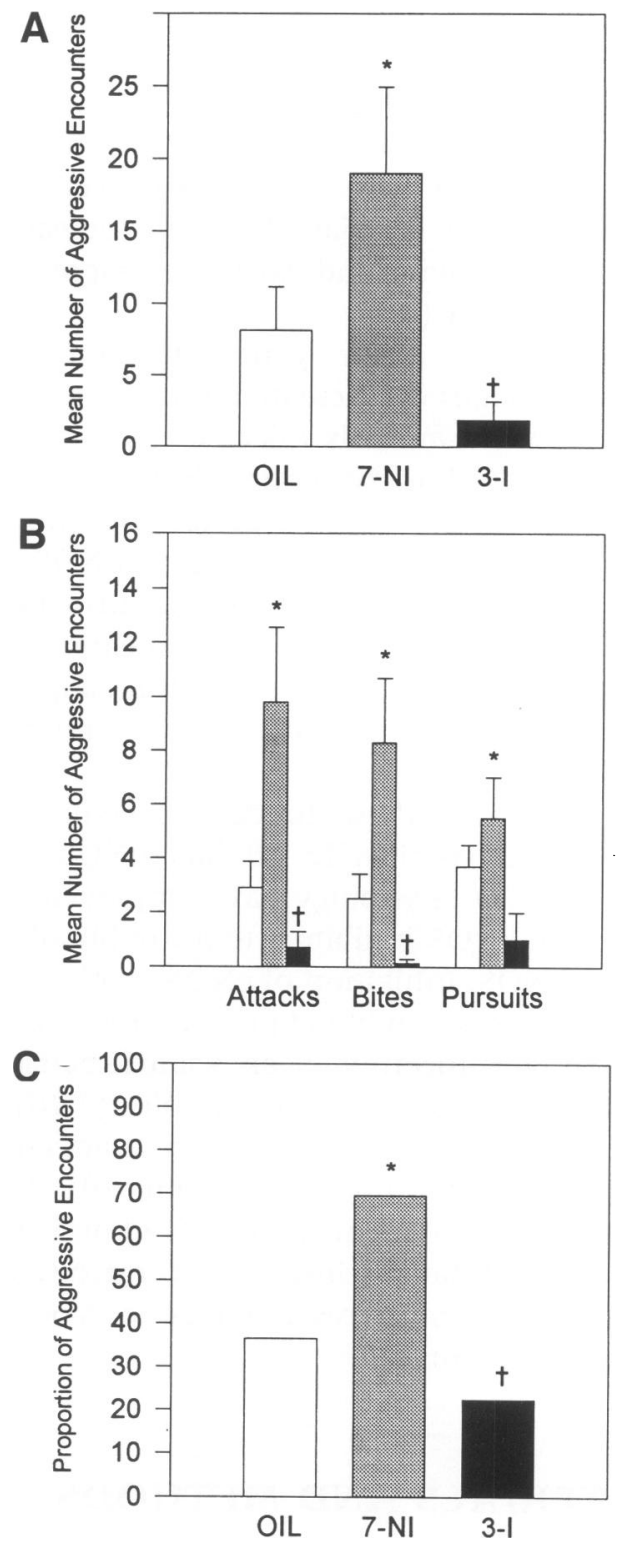

FIG. 1. Aggressive behavior in adult male mice treated with 7-nitroindazole (7-NI), 3-indazolinone (3-I), or oil-vehicle (oil) in a residentintruder model.

(A) Mean ( \pm SEM) number of aggressive encounters; (B) mean ( \pm SEM) number of attacks, bites, and pursuits; (C) proportion of total aggressive encounters demonstrated by resident males. Columns with no symbol or sharing the same symbol are statistically equivalent. Columns with different symbols denote statistically significant differences.

the number of attacks by 7-NI-treated animals quadrupled, while the number of bites almost tripled, with a lesser increase in the number of pursuits. The duration of each aggressive en- 
counter was also substantially increased in the 7-NI-treated animals as was the proportion of encounters that involved aggression.

Blinded observation of interactions between vehicle- and 7-NI-treated animals confirmed the quantified behavior. When placed together, the 7-NI-treated animals rapidly initiated aggressive behavior that they maintained even when the resident mouse adopted a submissive posture. It was necessary to separate the animals within 5 min to prevent serious injury. This behavior closely resembles that of nNOS- animals previously examined in our laboratory (4).

By contrast, 3-I-treated animals displayed diminished aggressive behavior. The mean number of aggressive episodes was reduced by more than $75 \%$ in 3-I-treated animals. The extent of diminished aggressive encounters was similar for attacks, bites, and pursuits. There was a similar diminution of duration of such encounters as well as a decrease in the proportion of attacks initiated by the resident mice.

We also evaluated aggressive behavior between drug-treated animals in groups. We placed groups of four vehicle-treated, 7-NI-, or 3-Itreated males together in an aquarium. In this model the duration and number of aggressive encounters almost doubled following 7-NI treatment (Fig. 2). There was some nonsignificant decrease in numbers of aggressive encounters in 3-I-treated mice.

Alterations in apparent aggressive behavior might derive from abnormalities in overall locomotor activity. We quantified overall locomotor activity and observed no differences between 7NI-, 3-I-, and vehicle-treated animals. We also measured locomotor activity of animals in an open-field test, a putative model for anxiety. We found no difference in open-field behavior among either of the drug-treated groups and vehicle-treated animals. Some drugs alter body temperature which can markedly influence behavior. We observed no difference in body temperature between drug- or vehicle-treated animals (data not shown).

\section{7-NI Depletes Neuronal Citrulline}

In behavioral studies employing enzyme inhibitors, it is crucial to ensure that enzyme inhibition occurs in the intact organism. Following our treatment regimen with 7-NI, NOS activity of brain homogenates was reduced by more than $90 \%$ (12). To evaluate NOS activity in the intact organism, we conducted immunohistochemical
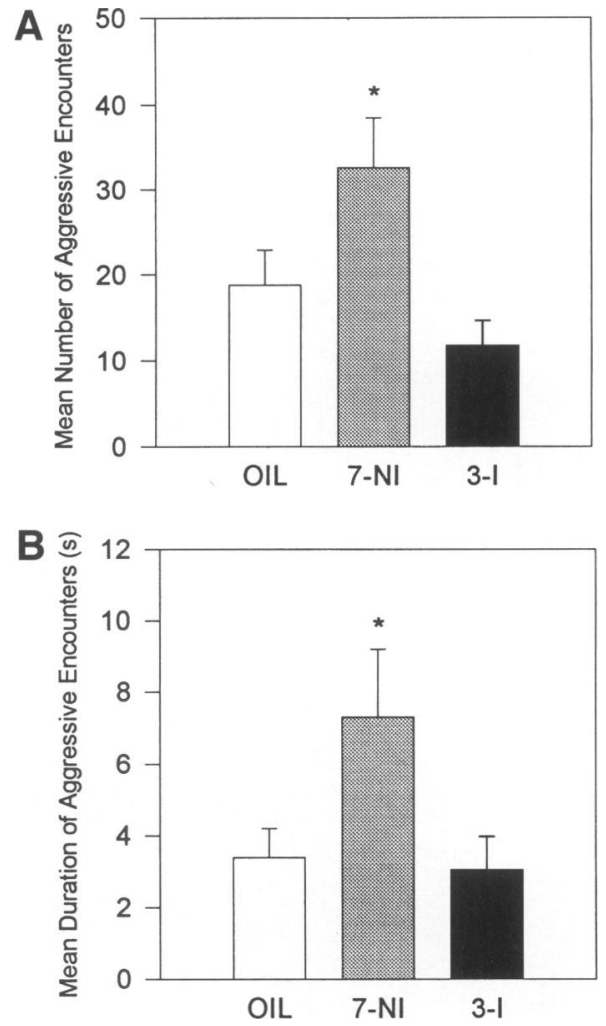

FIG. 2. Aggressive behavior in adult male mice treated with 7-nitroindazole (7-NI), 3-indazolinone (3-I), or oil vehicle (oil) in a grouped aggression in neutral arena model.

(A) Mean ( \pm SEM) number of aggressive encounters; (B) mean ( \pm SEM) duration of each aggressive encounter. Symbols and conventions are as in Fig. 1.

staining for citrulline, which is produced stoichiometrically with NO from NOS and which we have previously shown to faithfully reflect in vivo NOS activity (10). We observed a profound decrease in neuronal citrulline staining throughout the brain including the amygdala in the 7 NI-treated animals (Fig. 3). Thus, the treatment regiment for 7-NI that we have employed virtually abolishes the formation of citrulline and, presumably, NO in neurons. We also examined nNOS staining in all animals and observed no drug-induced alteration in the brain (Fig. 3).

\section{DISCUSSION}

In the present study we have employed 7-NI as a selective inhibitor of nNOS in intact animals to examine the role of NO in mediating aggressive behavior. When assayed with the three isoforms 


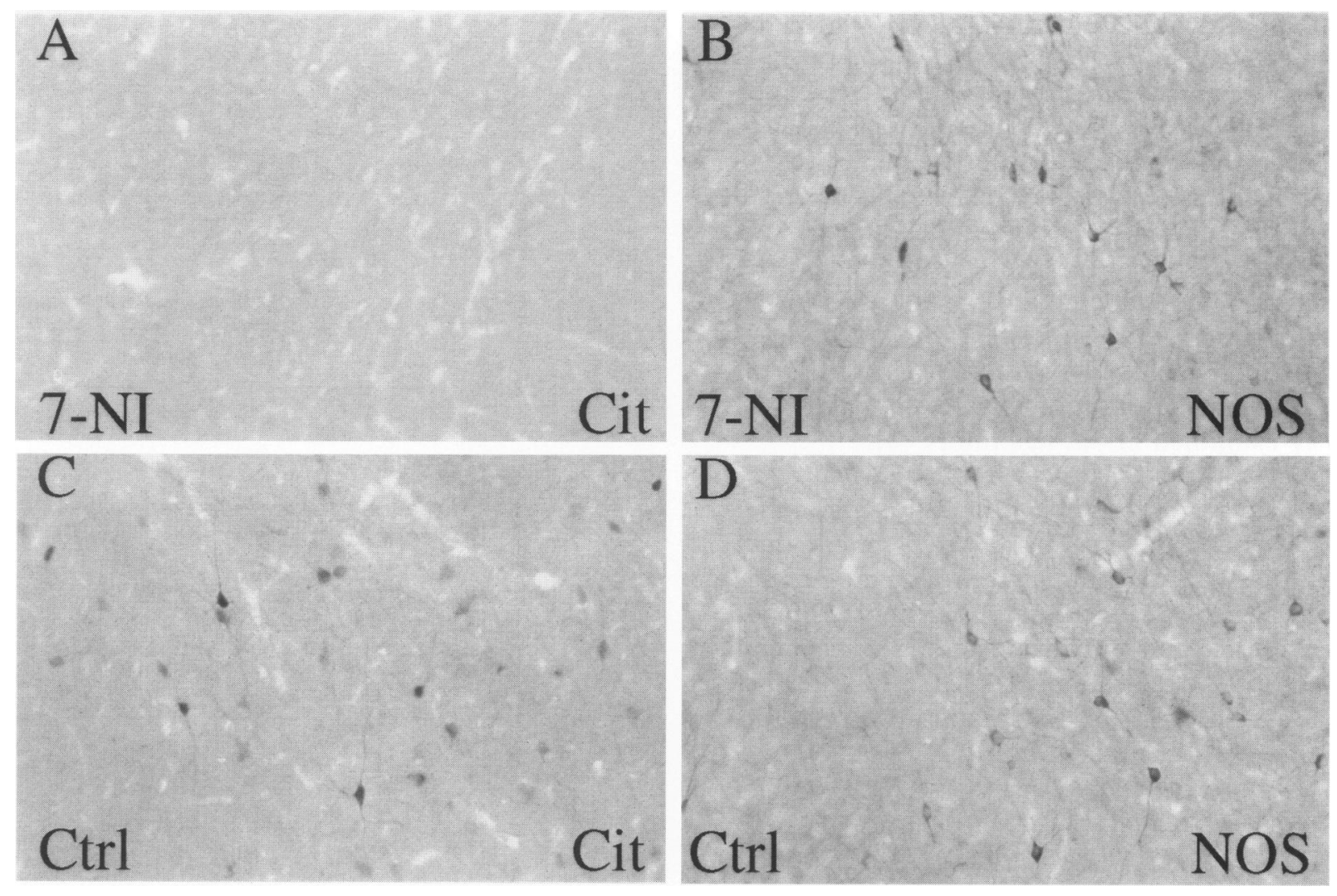

FIG. 3. In vivo inhibition of nNOS in animals treated with 7-nitroindazole.

Citrulline (Cit) and neuronal nitric oxide synthase (nNOS) staining in the dorsal amygdaloid area of animals treated with 7-NI or oil-vehicle (Ctrl). There is a virtual abolishment of neuronal citrulline staining in the 7-NI-treated group, while nNOS staining appears unchanged.

of NOS (endothelial, inducible, neuronal) in vitro, 7-NI displays similar potency in inhibiting all three (13). However, in intact animals, 7-NI inhibits NOS activity in brain extracts while not elevating blood pressure (9). It is not clear whether 7-NI fails to inhibit eNOS in intact animals because of lack of bioavailability in blood vessels or whether it inhibits eNOS but elicits some other effect that prevents hypertension. Conceivably, monitoring citrulline staining in blood vessels can clarify this issue.

Immunohistochemical staining revealed virtual abolition of neuronal citrulline in all brain regions examined following 7-NI treatment. This indicates that assays of NOS activity in brain homogenates underestimate the extent of inhibition. Indeed, chronic treatment with L-nitroarginine produces a similar outcome with $\sim 70 \%$ inhibition in brain homogenates but virtual abolishment of neuronal citrulline staining $(10,14,15)$. Presumably, when tissue is homogenized for enzyme assays, the drug is sufficiently diluted to diminish the extent of enzyme inhibition. Also, NOS activity in brain homogenates may be higher than in intact brain tissue because of dilution of endogenous inhibitors such as protein inhibitor of NOS (PIN) (16).

In assays of brain homogenates, a single dose of 7-NI inhibits NOS activity by $75-80 \%$. However, NOS activity recovers substantially in less than $1 \mathrm{hr}$ (12). With the protocol employed in this study, utilizing multiple injections of 7-NI, brain NOS activity also increases after the last administration of the drug, although not as rapidly as after a single dose of 7-NI (T. M. Dawson, personal communication). We conducted all of our behavioral studies $30 \mathrm{~min}$ following the last injection of 7-NI in order to maximize enzyme inhibition. We previously reported increases in sexual behavior by male nNOS- mice (4). Because these studies require several hours, we were unable to conduct such experiments during the period of maximal NOS inhibition.

The principal finding of the present study is 
the dramatic augmentation of aggressive behavior elicited by 7-NI. The pattern and extent of this aggressive behavior closely resembles behavior we previously reported in nNOS - male mice (4). The use of 7-NI resolves several concerns related to the gene knockout studies. Our nNOS- animals were generated by deleting exon- 2 of the nNOS gene (2). Two alternatively spliced forms of nNOS lacking exon-2, termed nNOS $\beta$ and nNOS $\gamma$, exist in the brain and are retained in the nNOS - mice (17). In in vitro assays, nNOS $\gamma$ is catalytically inactive in some (17) but not other studies (18), and nNOS $\beta$ exhibits catalytic activity comparable to that of parent nNOS (17). Overall NOS activity is reduced by more than $90 \%$ in nNOS - mice (2). However, in certain brain areas, such as the pedunculopontine nucleus and central cochlear nucleus, nNOS $\beta$ accounts for a major proportion of total nNOS mRNA in wild-type mice and is thus expressed at high levels in nNOS- mice (10). Other brain areas in the nNOS- mice, such as striatum and cerebral cortex, show a 2- to 3-fold upregulation in nNOS $\beta$ mRNA levels compared with wildtype mice (10). Conceivably, abnormal behavior in nNOS - mice could be a consequence of this increase in nNOS $\beta$ rather than a loss of the parent nNOS. Studies in mice with complete deletion of nNOS would be necessary to definitively address this question. However, the similar effects of 7-NI treatment and nNOS exon-2 deletion strengthen the conclusion that the abnormal aggressive behavior observed is due to the loss of the parent nNOS activity.

It has been suggested that aberrant behavior in knockout mice, including nNOS- animals, reflects admixture of genetic elements in the SvEv129 and C57BL/6J mice strains that are employed to create the knockouts $(18,19)$. Studies are currently underway backcrossing animals to a pure C57BL/6J background so that nNOSanimals will represent a pure C57BL/6J strain (T. M. Dawson, in preparation).

Genes that are "knocked out" have been deleted from the earliest embryonic stages, presumably leading to multiple compensatory alterations. Aberrant behavior could stem from these alterations rather than resulting directly from loss of the targeted gene. Enzyme inhibitors that inhibit specific isoforms of NOS are useful in addressing this issue.

Because excess production of NO may be pathophysiologic in conditions such as ischemic stroke $(20,21)$, there has been a substantial effort to develop nNOS inhibitors. Our findings of dra- matic augmentations of aggressive behavior soon after the administration of an nNOS inhibitor raise concerns about adverse sequelae of such agents.

\section{ACKNOWLEDGMENTS}

This work was supported by USPHS grants MH18501 and MH57757, a Research Scientist Award DA-00074 to S.H.S., and a gift of the Theodore and Vada Stanley Foundation, by USPHS grants NS01578 and NS-33277 and the Paul Beeson Faculty Scholar Award to T.M.D. and the National Alliance for Research on Schizophrenia to V.L.D., and by a Gustavus and Louise Pfeiffer Scholarship to M.J.L.E.

\section{REFERENCES}

1. Jaffrey SR, Snyder SH. (1995) Nitric oxide: A neural messenger. Annu. Cell. Dev. Biol. 11: 417-440.

2. Huang PL, Dawson TM, Bredt DS, Snyder SH, Fishman MC. (1993) Targeted disruption of the neuronal nitric oxide synthase gene. Cell 75: 1273-1286.

3. Huang Z, Huang PL, Panahian N, Dalkara T, Fishman MC, Moskowitz MA. (1994) Effects of cerebral ischemia in mice deficient in neuronal nitric oxide synthase. Science 265: 1883-1885.

4. Nelson RJ, Demas GE, Huang PL, Fishman MC, Dawson VL, Dawson TM, Snyder SH. (1995) Behavioural abnormalities in male mice lacking neuronal nitric oxide synthase. Nature 378: $383-386$.

5. Burnett AL, Nelson RJ, Calvin DC, Liu J-X, Demas GE, Klein SL, Kriegsfeld LJ, Dawson VL, Dawson TM, Snyder SH. (1996) Nitric oxide-dependent penile erection in mice lacking neuronal nitric oxide synthase. $\mathrm{Mol}$. Med. 2: 288-296.

6. O'Dell TJ, Huang PL, Dawson TM, Dinerman JL, Snyder SH, Kandel ER, Fishman MC. (1994) Endothelial NOS and the blockade of LTP by NOS inhibitors in mice lacking neuronal NOS. Science 265: 542-546.

7. Linden DJ, Dawson TM, Dawson VL. (1995) An evaluation of the nitric oxide/cGMP/ cGMP-dependent protein kinase cascade in the induction of cerebellar long-term depression in culture. J. Neurosci. 15: 5098-5105.

8. Good M. (1996) Targeted deletion of neuro- 
nal nitric oxide: A step closer to understanding its functional significance? Trends Neurosci. 19: 93-84.

9. Moore PK, Wallace P, Garren Z, Hart SL, Babbedge RC. (1993) Characterization of the novel nitric oxide synthase inhibitor 7-nitro indazole and related indazoles: Antinociceptive and cardiovascular effects. Br. J. Pharmacol. 110: 219-224.

10. Eliasson MJL, Blackshaw S, Schell MJ, Snyder SH. (1997) Neuronal nitric oxide synthase alternatively spliced forms: Prominent functional localizations in the brain. Proc. Natl. Acad. Sci. U.S.A. 94: 3396-3401.

11. Babbedge RC, Bland-Ward PA, Hart SL, Moore PK. (1993) Inhibition of rat cerebellar nitric oxide synthase by 7 -nitroindazole and related substituted indazoles. $B r$. J. Pharmacol. 110: 225-228.

12. Przedborski S, Jackson-Lewis V, Yokoyama R, Shibata T, Dawson VL, Dawson TM. (1996) Role of neuronal nitric oxide in 1-methyl-4pheny- 1,2,3,6-tetrahydropyridine (MPTP)induced dopaminergic neurotoxicity. Proc. Natl. Acad. Sci. U.S.A. 93: 4565-4571.

13. Bland-Ward PA, Moore PK. (1995) 7-Nitro indazole derivatives are potent inhibitors of brain, endothelium and inducible isoforms of nitric oxide synthase. Life Sci. 110: 225228.

14. Dawson VL, Kizushi, VM, Huang PL, Snyder SH, Dawson TM. (1996) Resistance to neu- rotoxicity in cortical cultures from neuronal nitric oxide synthase-deficient mice. $\mathrm{J}$. Neurosci. 16: 2479-2487.

15. Dwyer MA, Bredt DS, Snyder, SH (1991) Nitric oxide synthase: Irreversible inhibition by $\mathrm{L}-\mathrm{N}^{\mathrm{G}}$-Nitroarginine in brain in vitro and in vivo. Biochem. Biophys. Res. Commun. 176: 1136-1141.

16. Jaffrey SR, Snyder SH. (1996) PIN: An associated protein inhibitor of neuronal nitric oxide synthase. Science 274: 774-777.

17. Brenman JE, Chao DS, Gee SH, McGee AW, Craven SE, Santillano DR, Wu Z, Huang F, Xia H, Peters MF, Froehner SC, Bredt DS. (1996) Interaction of nitric oxide synthase with the postsynaptic density PSD-95 and alpha 1-syntrophin mediated by PDZ domains. Cell 84: 757-767.

18. Wang Y, Goligorsky MS, Lin M, Wilcox, JN, Marsden PA. (1997) A novel, testis-specific mRNA transcript encoding an $\mathrm{NH}_{2}$-terminal truncated nitric-oxide synthase. J. Biol. Chem. 272: 11392-11401.

19. Morris R. (1996) NOS and aggression. Trends Neurosci. 19: 277-278.

20. Faraci, FM, Brian JE. (1994) Nitric oxide and the cerebral circulation. Stroke 25: 692-703.

21. Dawson TM, Snyder SH. (1994) Gases as biological messengers: Nitric oxide and carbon monoxide in the brain. J. Neurosci. 14: 5147-5159.

Communicated by S. Snyder. Accepted July 10, 1997. 